\section{Tinjauan Atas Segmentasi, Penetapan Pasar Sasaran Dan Pemosisian KPR Pada PT Bank Tabungan Negara (Persero) KCP Dramaga Bogor}

\author{
Yusi Meilawati, Weman Suardy dan Ade Yusdira \\ Program Diploma III Manajemen Pemasaran, Institut Bisnis dan Informatika Kesatuan \\ E - Mail : yusi,meilawati@ibik.ac.id
}

Implementation of

S-T-P Strategy in Banking Sector

\section{ABSTRACT}

This research was conducted by Bank BTN Kcp Dramaga. Bank BTN is one of the banks that has increased performance from period to period as evidenced by Bank BTN consistently improving services through priority banking with a product, namely bancassurance, in collaboration with several parties. In addition, Bank BTN is consistent in its core business (Core Bussiness) in housing finance in accordance with the visit of Bank BTN itself which is the leading bank in financing. Bank $B T N$ is more comfortable with mortgage products or residential financing. Mortgage is defined as a loan provided by the Bank to the debtor which is used to purchase or pay for a residential building and land to be owned or occupied. there are products that are offered such as subsidized BTN KPR or you can choose non-subsidized BTN KPR. The purpose of the results of this study to determine 1). How to identify the factors for implementing Segmentation, determining target markets and positioning mortgage products, 2). KPR product efforts at PT Bank Tabungan Negara Kcp Dramaga Bogor in segmentation, target market determination and positioning and 3). Obstacles in implementing segmentation, determining target markets and positioning mortgage products at PT Bank Tabungan Negara Kcp Dramaga. The results of the discussion show that segmentation, market determination and positioning of mortgage products have increased enough to be able to realize it and Bank BTN has also increased market segments to maintain a good target market for its consumers, can achieve goals with maximum sales and increase targets for quality consumers

Keywords: banking, segmenting, targeting, positioning

\section{ABSTRAK}

Penelitian ini dilakukan Bank BTN Kcp Dramaga. Bank BTN merupakan salah satu Bank memiliki kinerja meningkat dari periode ke periode terbukti dengan konsisten Bank BTN meningkatkan pelayanan melalui prority Banking dengan produk yaitu bancassurance melakukan kerja sama dengan beberapa pihak. Selain itu, Bank BTN konsisten pada bisnis inti (Core Bussiness) dalam pembiayaan perumahan sesuai dengan visit Bank BTN sendiri yang menjadi Bank termuka dalam pembiayaan. Bank BTN lebih dikenak dengan produk KPR atau pembiayaan rumah tinggal. KPR didefinisikan sebagai kredit yang diberikan oleh Bank kepada debitur yang digunakan untuk membeli atau membayar sebuah bangunan rumah tinggal dan tanahnya guna dimiliki atau dihuni. adanya produk ynag ditawarkan semacam KPR BTN subsidi atau bisa memilih KPR BTN non subsidi. Tujuan dari hasil penelitian ini untuk mengetahui 1). Bagaimana mengidentifikasi faktor-faktor penerapan Segmentasi, penetapan pasarsasaran dan pemosisian produk KPR, 2). Upaya produk KPR pada PT Bank Tabungan Negara Kcp Dramaga bogor dalam Segmentasi, penetapan pasarsasaran dan pemosisian dan 3). Hambatan dalam penerapan Segmentasi, penetapan pasarsasaran dan pemosisian produk KPR pada PT Bank Tabungan Negara Kcp Dramaga. Hasil pembahasan menunjukkan bahwa Segmentasi, penetapan pasasaran dan pemosisian produk KPR cukup meningkat dapat mampu merealisasikan dan Bank BTN juga meningkatkan segmen pasar untuk mempertahankan target pasar yang baik terhadap konsumennya dapat mencapai tujuan

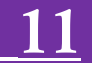

Submitted

JANUARI 2021

Accepted

JULI 2021 
Implementation of S-T_P Strategy in Banking Sectore
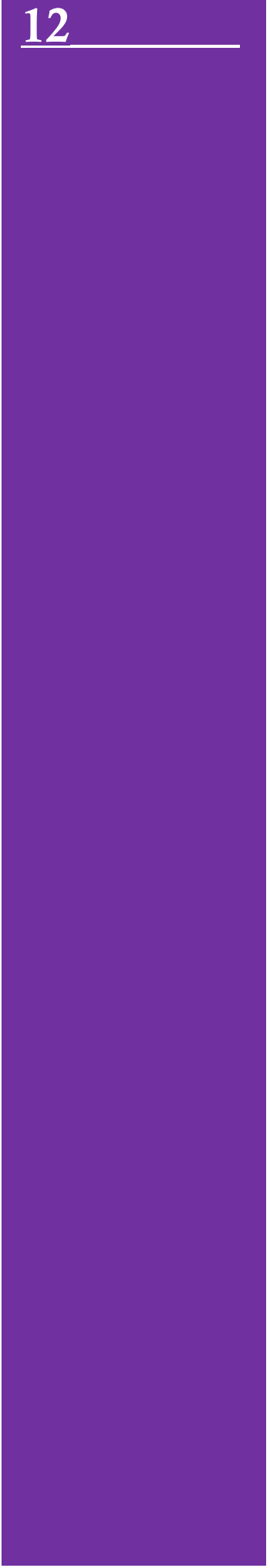

dengan penjualan yang maksimal serta meningkatkan target pada konsumen yang berkualitas.

Kata Kunci: bank, segmentasi, targeting, positionig

\section{PENDAHULUAN}

Bank mempunyai fungsi dan peran penting dalam perekonomian nasional. jika dilihat dari kondisi masyarakat sekarang, jarang sekali orang yang tidak mengenal dan tidak berhubungan dengan Bank. Hampir semua orang berkaitan dengan lembaga keuangan pada mulanya kegiatan perbankan dimulai dari jasa pertukaran uang, sehingga dalam sejarah perbankan arti dikenal sebagai tempat menukar uang dimana kegiatan penukaran uang tersebut sekarang dikenal dengan pedagang valuta asing (Money Changer).

Persaingan antar bank telah mencapai tahapan yang semakin kompetitif sehingga membuat pihak-pihak yang terkait dengan lembaga keuangan seperti Bank haruslah memiliki usaha-usaha produktif untuk menarik nasabah sebanyak-banyaknya. Dengan meningkatkan persaingan antar Bank yang semakin ketat dalam menarik nasabah sebanyak-banyaknya, untuk itu bank harus dapat memberikan inovasi terhadap produk serta layanan jasa yang dimiliki oleh Bank tersebut. Produk Bank tersebut haruslah dapat memberikan kemudahan, serta dapat memenuhi kebutuhan nasabahnya, begitu pula dengan layanan jasa, nasabah akan tertarik apabila bank tersebut memiliki layanan jasa yang menarik.

Bank sebagai lembaga perantara keuangan berperan penting dalam perekonomian yang salah satunya menghimpun dana dari masyarakat dan kemudian menyalurkan kembali kemasyarakat serta memberikan jasa Bank lainnya. Didalam menjalankan kegiatan operasionalnya, Bank harus memiliki STP (Segmentasi, Targeting,Positioning). Selain itu, Bank sebagai penghimpunan dana tentunya juga harus dapat memberikan persaingan antar Bank yang terjadi pada masa saat ini agar nasabah menjadi pelanggan tetap dalam kegiatan transaksi perbankan.

Seiring dengan perkembangan perbankan di Indonesia saat ini diharapkan membawa kearah kemajuan bagi perbankan Indonesia guna mampu menghadapi dan mengatasi semua tentang perekonomian dan perbankan internasional serta membawa manfaat yang besar bagi masyarakat kearah sejahteraan yang berkeadilan.

Bank BTN merupakan salah satu Bank yang memiliki kinerja meningkat dari periode ke periode terbukti dengan konsistensi Bank BTN menigkatkan pelayanan melalui Priority Banking dengan produk yaitu Bancassurance melakukan kerjasama dengan beberapa pihak perusahaan asuransi sehingga disisi lain kerja sama ini memberikan keuntungan bagi Bank BTN dalam penambahan profit atau laba perusahaan. Selain itu, Bank BTN konsisten pada bisnis inti (Core Bussiness) dalam pembiayaan perumahan sesuai dengan visit Bank BTN sendiri yang ingin menjadi Bank termuka dalam pembiayaan. Bank BTN lebih dikenal dengan produk KPR atau pembiayaan rumah tinggal. Dimana pasar yang sangat luas ini menjadi kesempatan emas bagi bank yang telah terkenal dengan program KPR. KPR didefinisikan sebagai kredit yang diberikan oleh bank kepada debitur yang digunakan untuk membeli atau membayar sebuah bangunan rumah tinggal dengan tanahnya guna dimiliki atau dihuni. tujuan adanya kredit kepemilikan rumah yakni membantu para nasabah yang memiliki rumah tetapi tidak mempunyai uang secara Cash atau tunai dalam jumlah yang banyak. BTN lebih menekankan pada pembelian tempat tinggal atau rumah kerana rumah merupakan salah satu dari kebutuhan primer yang mempunyai sifat harus dimiliki setiap orang.

Adanya produk yang ditawarkan semacam KPR BTN Subsidi atau bisa memilih KPR BTN Non Subsidi. KPR BTN Subsidi yaitu kredit kepemilikan rumah program kerja sama dengan kementerian pekerjaan umum dan perumahan rakyat dengan suku bunga rendah, cicilan ringan dan tetap sepanjang jangka waktu kredit, terdiri atas KPR untuk pembelian rumah tapak dan rumah susun, sedangkan KPR BTN Non subsidi yaitu kredit 
pemilikan rumah dari Bank BTN untuk keperluan pembelian rumah dari Developer atau Non Developer, baik untuk pembelian rumah baru atau second, pembelian rumah belum jadi (Indent) maupun Take Over kredit dari Bank lain. dan pemerintah mengharapkan tingkat kemiskinan indonesia semakin ditekan.

Melihat jenis segmen yang ditawarkan oleh program KPR BTN membuat banyak orang tertarik untuk melakukan pengajuan kredit rumah. Banyak yang berhasil samapi lunas dan ada juga sebagian yang terdapat masalah didalam proses kreditnya. Untuk mengajukan kredit rumah KPR BTN haruslah dengan perjanjian kredit yang sesuai dengan peraturan yang berlaku.

Sejak tahun lalu perseroan terus berusaha memperbaiki kualitas kredit, berusaha mengolah dan mengalokasikan keuangan dengan bank dan meningkatkan kualitas dari produk-produk yang ditawarkan sehingga mampu menarik perhatian masyarakat dan mempertahankan kepercayaan masyarakat.

Sampai sejauh ini Bank BTN tetap fokus dibidang properti lainnya seperti dibidang properti dan perumahan dengan target sebesar $15 \%$ tahun sebelumnya. dan jumlah sekitar Rp. 140 miliar sampai tingkat suku bunga KPR pada tahun ini berkisar Rp. 11\%-12\%.

Strategi bisnis perencanaan pemasaran produk dan jasa ini , ada 3 komponen tersebut adalah Segmentasi, Penetapan Pasar sasaran dan Pemosisian yang pada hakekatnya digunakan untuk meningkatkan volume penjualan KPR.

Pelayanan yang berkualitas dan memuaskan akan memberikan suatu dorongan kepada nasabah untuk selalu menjalin hubungan yang kuat dan erat dengan Bank BTN. Pihak Bank BTN tentunya dapat meningkatkan kualitas dalam pelayanan dan menambahkan tingkat kepuasan nasabah dengan cara memaksimumkan pengalaman yang menyenangkan dan meminimumkan pengalaman yang kurang menyenangkan bagi para nasabah tersebut. Apabila nasabah belum puas dengan apa yang mereka dapatkan dari KPR di Bank BTN. Secara tidak langsung hal ini akan sangat membantu Bank BTN dalam meningkatkan segmentasi pada KPR.

Dalam memperoleh nasabah yang loyal terhadap suatu produk tertentu, Bank BTN haruslah memiliki kelebihan atau keunggulan tertentu yang tidak dimiliki oleh para kompetitornya dengan kata lain harus dibutuhkan Segmentasi, Penetapan Pasar Sasaran dan Pemoisian. Maka pemosisian dari Bank BTN dapat membuka peluang. Sehingga banyaknya peminat KPR untuk kalangan menengah kebawah yang mayoritas adalah nasabah Bank BTN yang menjadi favorit dari sekian banyak Bank. dan Bank BTN siap berlomba dengan kompetitor-kompetitor di bidang yang serupa untuk meningkatkan jumlah nasabah dan mencapai targetnya. memberi kepuasan bagi nasabah menjadi loyal bagi Bank BTN serta meraih laba untuk terus menjadikan Bank BTN semakin kuat dan terpercaya.

Berdasarkan latar belakang yang dikemukakan diatas, maka rumusan masalah yang diajukan sebagai berikut :

1. Bagaimana Segmentasi,Penetapan Pasar sasaran dan Pemosisian Produk KPR yang dilakukan oleh Bank BTN Kcp Dramaga Bogor?

2. Apa yang menjadi hambatan dalam penerapan Segmentasi, Penetapan Pasar sasaran dan Pemosisian KPR pada Bank BTN Kcp Dramaga Bogor?

3. Bagaimana cara Bank BTN Kcp Dramaga Bogor dalam upaya peningkatan Segmentasi, Penetapan Pasar sasaran dan Pemosisian pada KPR?

Maksud dari pembahasan ini adalah untuk mengelola data infomasi yang diperoleh dari objek menganalisis masalah yang ada sehingga dapat diperoleh hasil untuk dikembangkan kedalam penulisan tujuan dari pembahasan. Tujuan pembahasan ini adalah sebagai berikut : (1) Untuk mengetahui Segmentasi, Penetapan Pasar sasaran dan Pemosisian KPR yang dilakukan pada Bank BTN Kcp Dramaga Bogor. (2) Untuk mengetahui hambatan yang dihadapi dalam penerapan Segmentasi, Penetapan Pasar sasaran dan Pemosisian KPR pada Bank BTN Kcp Dramaga Bogor. (3) Untuk mengetahui bagaimana dalam upaya peningkatan Segmentasi, Penetapan Pasar sasaran dan Pemosisian KPR pada Bank BTN Kcp Dramaga Bogor. 


\section{HASIL DAN PEMBAHASAN}

\section{Sejarah Perusahaan}

Dengan maksud untuk mendidik masyarakat agar gemar menabung, pemerintah Hindia-Belanda melalui Koninklijk Besluit No. 27 tanggal 16 Oktober 1897 mendirikan Postpaar Bank. Kemudian terus hidup dan berkembang serta tercatat hingga tahun 1939 telah memiliki 4 (empat) cabang yaitu Jakarta, Medan, Surabaya, dan Makasar. Pada tahun 1940 kegiatannya terganggu, sebagai akibat penyerbuan Jerman atas Netherland yang mengakibatkan penarika tabungan besar-besaran dalam waktu yang relatif singkat. Namun demikian keadaan keuangan Postpaar Bank pulih kembali pada tahun 1941. Tahun 1942 Hindia Belanda menyerah tanpa syarat kepada pemerintah Jepang. Jepang membekukan kegiatan Postpaar Bank dan mendirikan Tyokin Kyoku hanya mendirikan satu cabang yaitu cabang Yogyakarta.

Proklamasi kemerdekaan Republik Indonesia tanggal 17 Agustus 1945 telah memberikan inspirasi kepada Bapak Darmosoetanto R.I. dan terjadilah penggantian nama menjadi kantor tabungan pos. Bapak Darmosoetanto ditetapkan oleh pemerintah R.I. menjadi Direktur yang pertama. Tugas pertama Kantor Tabungan Pos tidak berumur panjang. Karena agresi Belanda (Desember 1946) mengakibatkan didudukinya semua kantor, termasuk Kantor Cabang dari Kantor Tabungan Pos hingga 1949. Saat Kantor Tabungan R.I. sejak kelahirannya dan sampai berubah nama Bank Tabungan Pos R.I. lembaga ini bernaung dibawah Kementrian Perhubungan.

Banyaknya kejadian bernilai sejarah sejak tahun 1950 tetapi yang substantif bagi sejarah BTN adalah dikeluarkanya Undang-Undang Darurat No. 9 Tahun 1950 Tanggal 9 Febuari 1950. Kejadian ini mengubah nama POSTPAARBANKIN INDONESIA berdasarkan Staatsblat No. 295 tahun 1941 menjadi Bank Tabungan Pos dan memindahkan Induk Kementrian dari Kementrian Perhubungan ke Kementrian Keuangan dibawah Menteri Urusan Bank Sentral. Walaupun dengan Undang-Undang Darurat tersebut dikukuhkan dengan UU No. 36 tahun 1953 tanggal 18 Desember 1953. Perubahan nama dari Bank Tabungan Pos menjadi Bank Tabungan Negara didasarkan pada PERPU No. 4 tahun 1963 tanggal 22 Juni 1963 yang kemudian dikuatkan dengan Undang-Undang No. 2 tahun 1964 tanggal 25 mei 1964.

Penegasan status Bank Tabungan Negara sebagai Bank Milik Negara ditetapkan dengan Undang-Undang No. 20 tahun 1968 tanggal 19 Desember 1968 yang sebelumnya (sejak tahun 1964) Bank Tabungan Negara menjadi BNI unit V. jika tugas utama saat pendirian Postspaarbank (1897) sampai dengan Bank Tabungan Negara ditambah tugasnya yaitu memberikan pelayanan KPR dan untuk pertama kalinya penyaluran KPR terjadi pada tanggal 10 Desember 1976. Karena tanggal 10 Desember diperingati sebagai hari KPR bagi BTN. Bentuk hukum BTN mengalami perubahan lagi pada tahun 1992, yaitu dengan dikeluarkan PP No. 24 tahun 1992 tanggal 29 April 1992 yang merupakan pelaksanaan dan UU No. 7 tahun 1992 bentuk hukum BTN, berubah menjadi Perusahaan Perseroan. Sejak itu nama BTN menjadi PT. Bank Tabungan Negara (Persero) dengan Call Name BTN. Berdasarkan kajian Consultan Independent, Price Waterhouse Coopers. Pemerintah melalui Menteri BUMN dalam surat Nomor S-544/mmbu/2002 tanggal 21 Agustus 2002 memutuskan BTN sebagai Bank Umum dengan focus bisnis pembiayaan perumahan tanpa subsidi.

Sukses KPR dengan realisasi pertama di semarang pada tahun 1976 tersebut telah membawa keyakinan manajemen BTN untuk menjadikan bisnis perumahan tersebut sebagai bisnis utama BTN. Hal ini tampak jelas pada misi BTN.

Bank BTN menjadi wadah penyaluran pembiayaan KPR terbesar di Indonesia KPR BTN telah memberikan peran meningkatkan kesejahteraan hidup masyarakat indonesia melalui terpenuhinya kebutuhan hunian bagi masyarakat. Pemerintah dalam program pembangunan perumahan nasional. KPR BTN juga ikut mendorong tumbuhnya ekonomi kerakyatan.

Besar Bank BTN memiliki pangsa pasar yang yang tidak dapat dimasukin oleh Bankbank lain. Dengan kekuatan infrastruktur bisnis yang dimiliki oleh Bank BTN, jika Bank 
ini akan tetap menjadi penguasa di bisnis pembiayaan perumahan, terutama KPR bersubsidi.

Akhirnya Sejarah Mencatat dengan sukses BTN dalam bisnis perumahan melalui fasilitas KPR tersebut telah membawa status BTN ini menjadi PT. Bank Tabungan Negara (Persero) pada tahun 1992. Status persero ini memungkinkan BTN bergerak lebih luas lagi dengan fungsinya sebagai Bank Umum. dan memang untuk mendukung bisnis KPR tersebut, BTN mulai mengembangkan prduk-produk layanan perbankan sebagaimana layaknya Bank Umum. BTN juga memiliki Produk Tabungan, Giro, Deposito, atau Layanan yang dimiliki oleh Bank lain.

\section{Visi dan Misi Perusahaan}

Visi Bank BTN :

Terdepan dan terpercaya dalam memfasilitasi sektor perumahan dan jasa layanan keuangan keluarga.

Misi Bank BTN :

Berperan aktif dalam medukung sektor perumahan, baik dari sisi penawaran maupun dari sisi permintaan, yang terintegrasi dalam sektor perumahaan Indonesia.

1. Memberikan layanan unggul dalam pembiayaan kepada sektor perumahan dan kebutuhan keuangan keluarga.

2. Meingkatkan keunggulan kompetitif melalui inovasi pengembangan produk, jasa dan jaringan strategisberbasis digital.

3. Menyiapkan dab mengembangkan human capital yang berkualitas, profesioanal, dan memiliki integritas tinggi.

4. Meningkatkan shareholder value dengan fokus kepada peningkatkan pertumbuhan profitabilitas sesuai dengan prinsip kehati-hatian dan Good Corporate Governance.

5. Memedulikan kepentingan masyarakat sosial dan lingkangan secara berkelanjutan.

\section{Lokasi Perusahaan}

Lokasi sebuah perusahaan sangat menentukan kelangsungan hidup dari perusahaan yang bersangkutan dimasa yang akan datang. Pemilihan lokasi PT. Bank Tabungan Negara (Persero) Tbk Kantor Cabang Bogor yang terletak J1. Pengadilan No. 13-15 Bogor memiliki pertimbangan-pertimbangan tersendiri. Pertimbangan-pertimbangan yang dikemukakan, antara lain sebagai berikut :

1. BTN adalah Bank yang kerjasama dengan proyek perumnas dan beberapa pengembangan swasta yang berada di wilayah Bogor sehingga BTN membuka cabang di Bogor.

2. Lokasi BTN ditengah kota sehingga strategis untuk Kantor Cabang di bogor yang mebawahi beberapa Kantor Cabang Pembantu. Wilayah usaha BTN tersebar diseluruh wilayah Indonesia dengan jumlah 45 Kantor Cabang, sedangkan di bogor terdapat Satu Kantor Cabang dan enam Kantor Cabang Pembantu dan Sebelas Kantor Kas.

Segmentasi, Penetapan pasarsasaran dan Pemosisian KPR yang dilakukan Oleh PT

\section{Bank Tabungan Negara (Persero) kcp Dramaga Bogor}

Salah satu komponen yang mendukung dalam Segmentasi, Penetapan pasarsasaran dan pemosisian yaitu bagaimana Segmentasi, Penetapan pasarsasaran dan pemosisian yang digunakan oleh suatu proses atau badan usaha. Segmentasi, Penetapan pasarsasaran dan pemosisian yang diambil perusahaan dan memasarkan produk akan sangat mempengaruhi hasil yang diperoleh. Dengan adanya kegiatan tersebut, penulis mencoba membahas mengenai Segmentasi, pasarsasaran dan pemosisian pada produk KPR yang digunakan untuk meningkatkan dan mencapai tujuan Bank BTN Kcp Dramaga yaitu penjualan yang maksimal serta bagaimana cara meningkatkan pelayanan pada konsumen sesuai dengan hasil tersebut, penulis akan mencoba membandingkan penelitian yang dilakukan Bank BTN dan teori yang di peroleh.

Didalam teori, Segmentasi Targeting dan Positioning yang meliputi Segmentasi, Pembidik, dan Penetapan posisi. Perusahaan mencari sejumlah kebutuhan dan kelompok 
yang berada dipasar, membidik kebutuhan dan kelompok yang dapat dipuaskan dengan cara yang unggul dan selanjutnya memosisikan tawarannya khas perusahaan tersebut.

1. Segmentasi (Segmentation)

Segmentasi merupakan bagian yang paling penting dalam menentukan kesuksesan suatu perusahaan. Segmentasi adalah proses membagi pasar yang bersifat heterogen kedalam beberapa segmen sehingga masing-masing segmen cenderung bersifat homogen dalam segala aspek perubah segmentasi utama yang digunakan untuk pasar konsumen sebagai berikut:

a. Segmentasi Geografis

Merupakan suatu aktivitas pemasaran yang dilakukan dengan membagi-bagi pasar dalam beberapa unit geografis yang berbeda-beda seperti daerah, populasi, kepadatan dan iklim.

b. Segmentasi Demografis

Pengelompokan konsumen berdasarkan usia, jenis kelamin, pendidikan, pekerjaan, dan pendapatan. Sehingga dapat diketahui kebutuhan dan keinginan konsumen yang berbeda-beda pada setiap variabel tersebut.

c. Segmentasi Psikografis

Metode yang digunakan untuk mengelompokan calon, pelanggan saat ini atau sebelum dengan ciri-ciri kepridadian mereka, keyakinan, nilai sikap, dan gaya hidup.

d. Segmentasi Perilaku

Merupakan pasar yang membagi menjadi kelompok homogen dengan dasar pola penggunaan produk atau pengetahuan terhdap produk.

2. Pasarsasaran (Targeting)

Pasarsasaran adalah proses mengevaluasi dan memilih beberapa segmen pasar yang dinilai paling menarik untuk dilayani dengan program pemasaran spesifik perusahaan.

\section{Pemosisian (Positioning)}

Positioning adalah strategi yang berusaha menciptakan diferensiasi yang unik dalam benak pelanggan sasaran, sehingga terbentuk citra merek atau produk yang lebih unggul dibandingkan dengan merek produk pesaing. Hasil akhir penetapan posisi adalah keberhasilan penciptaan proporsi nilai yaitu alasan meyakinkan pelanggan untuk membeli produk perusahaan.

Adapun secara praktek untuk mengetahui Segmenting, Targeting dan Positioning produk KPR di bank BTN bogor.

1. Segmentasi (Segmenting)

dalam segmentasi pasar untuk produk KPR meningkat mampu merealisasikan kenaikan KPR nonsubsidi sebesar 12,9\% menjadi 20,95\% hal ini diluar Trend bisnis perbankan. Selain itu, dengan pangsa pasar KPR terbesar akan terus mendukung program sejuta rumah pemerintah yang disebut KPR subsidi sehingga Bank BTN tetap berkonstribusi pada program sejuta pemerintah. dan Bank BTN juga fokus pada perbaikan kualitas bisnis yaitu portofolio kredit dan funding yang mampu layanan nasabah. Karena lebih penting bagi Bank BTN untuk menghadapi peluang dan tantangan tahun 2020 dengan menyiapkan fondasi bisnis sejalan dengan model bisnis yang menghadaptasi dinamika pasar. Segmen pasar pada KPR cenderung bersifat homogen dalam segala aspek perubahan yang digunakan untuk pasar konsumen sebagai berikut :

a. Segementasi Geografis

Dalam segmentasi geografis untuk Produk KPR dilihat dari segi wilayah dimana yang ingin mengambil produk KPR subsidi atau KPR non subsidi. Untuk produk KPR tersebut yang posisi atau tempatnya berada ditengah-tengah kota harganya tinggi, semakin tempatnya berada di tengah-tengah kota harganya makin naik atau meningkat dalam target pasarnya.

b. Segmentasi Demografis 
Berdasarkan data untuk membeli KPR tersebut didominasi oleh masyarakat dengan kisaran usia 25-35 tahun. Para generasi muda ini sudah mulai banyak mencari infomasi dalam pembelian rumah. Dan untuk mengajukan KPR syarat yang paling utama adalah dilihat dari usia. Batas maksimal umur diterapkan oleh Bank adalah 50 tahun sampai 55 tahun saat cicilan KPR lunas, jika melewati batas tersebut kemungkinan besar akan menolak.

c. Segmentasi Psikografis

Dalam mendapatkan hasil yang terbaik penjual harus memiliki metode pendekatan yang berbeda-beda tergantungkepadan calon konsumennya dengan karakter konsumen yang ada akan dapat memaksimalkan hasil akhir yang ingin didapatkan dari calon konsumen untuk hasil akhirnya berupa keputusan konsumen yang dibuat calon konsumen tersebut dilihat dari karakter konsumen seperti konsumen potensial yang biasanya telah menunjukan karakter terhadap produk atau jasa yang dijul, baik melalui pengisian form contact, pertanyaan-pertanyaan yang diajukan kepada marketing channel yang miliki atau setidaknya telah mengunjungi website.

d. Segmentasi Perilaku

Dalam status penggunaan tingkat status keloyalan biasanya konsumen yang dimiliki karakter konsumen yang ada jika dilihat dari persesif penjual. Untuk memaksimalkan penjualan, harus melakukan setiap tipe konsumen degan berbeda sesuai kebutuhan dan sifat masing-masing konsumen.

2. Pasarsasaran (Targeting)

Pada tahap ini dalam menentukan target pasar produk KPR pada Bank BTN adalah dengan menentukan pasar sasaran berdasarkan evaluasi segmen pasar. Dalam target produk KPR pada akhir Febuari 2020 untuk penyaluran Kredit kepemilikan rumah atau KPR dengan aneka promosi diantaranya suku bunga KPR yang terjangkau dari hasil kolaborasi dan diskon biaya asuransi, provisi dan lain sebagainya. Bank BTN menarik lebih dari 200.000 orang. Dan nilai ijin prinsip KPR tersebut lebih tinggi dibandingkan target awal yang dibidik perseroan yaitu sebesar Rp. 3 Trilliun. Dan seperti yang diketahui APBN menganggarkan Rp. 11 Triliun untuk memfasilitasi subsidi pembiayaan 102.500 unit pada tahun 2020. Jumlah unit rumah yang mendapatkan subsidi tersebut lebih rendah dari tahun 2018 yang sebesar 280.000 unit dan tahun 2019 yang mencapai 162.00 unit. Meski, alokasi APBN tidak selalu meningkat, namun konstribusi Bank BTN terhadap program sejuta rumah tetap tinggi. Bank BTN, sejak tahun 2015 ketika program tersebut bergulir, Bank BTN telah menyalurkan pembiayaan untuk sekitar 3,10 juta unit, baik berbentuk KPR subsidi maupun non subsidi. Dan untuk pertumbuhan KPR non subsidi bisa tumbuh dikisaran $10-12 \%$ atau menyamai pertumbuhan kredit secara umum yang oleh Bank Indonesia pada tahun 2020 karena banyak faktor yang mendukung.

3. Pemosisian (Positioning)

Pemosisian Bank BTN dikredit perumahaan memang sangat jelas dari total kredit yang ada 89,9\% merupakan kredit KPR. Bank BTN menyasar KPR kelas menengah bawah meski nilainya tidak terlalu besar, rupanya konsumen pada segmen ini memiliki daya beli yang kuat untuk mencicil rumah. Dari total kredit perumahan senilai Rp.11 Triliun yang memfasilitasi subsidi. Sedangkan KPR non subsidi yang memiliki Range lebih dari Rp. 200-300 juta. Dalam hal ini, calon nasabah bisa mendapatkan petunjuk terhadap proses pengajuan kredit selama satu hari. Selanjutnya, Bank BTN akan mempromosikan aplikasi yang masuk dalam waktu lima hari, mulai dari pengecekan kelengkapan dokumen rumah, pendapatan calon debitur, dan lainnya. Meski menyasar kelangan menengah bawah, Bank BTN mampu mengklaim atau mampu menghadirkan layanan setara perusahaan kelas dunia. Bank BTN juga bergabung dalam World Savings and Retail Banking Institute (WSBI) untuk memperluas jaringan hingga keluar negeri, memperkuat Channel berbagai Provinsi Indonesia, dan penerapan Digital Banking untuk mempercepat proses pelayanan. Meski berurusan dengan debitur dalam jumlah banyak, bukan berarti Bank BTN merupakan prinsip Good corporate governance (GCG). Disisi back end back, Bank BTN 
memperkuat sistem dan SDM dibagian Collection. Selain itu, harus mendekatkan diri dengan konsumen melalui berbagai cara atau bisa mulai dari website, pameran perumahan, serta memperkuat relasi dengan jaringan agen. Bank BTN menjadi Bank KPR dengan Market share terbesar di Indonesia dengan porsi 30,6\% disektor non subsidi. Sedangkan di KRP-FLPP-BBTN memiliki Market share hingga 98\%.

\section{Hambatan dalam Penerapan Segmentasi, Penetapan pasarsasaran dan pemosisian produk KPR pada PT Bank Tabungan Negara (Persero) Kcp Dramaga Bogor.}

Dalam meningkatkan suatu usaha, banyak rintangan yang harus kita hadapi dalam penerapan segmentasi, penetapan pasarsasaran dan pemosisian yang baik. Adapaun faktor-faktor yang berpengaruh signifikan tehadap STP yaitu sebagai berikut :

1. Proses pembiayaan KPR Bank BTN seperti misalnya legalitas rumah tanah, pemilihan notaris yang kurang hati-hati dalam melakukan proses KPR, karena terkadang ada notaris yang tidak bertanggung jawab seperti data-data yang dibutuhkan tidak selesai di buat, hal tersebut harus ada yang back up dan mengatasinya. Para pihak bisa merinci hal dan kewajiban masing-masing pihak pada akad pembiyaan untuk mendefinisikan batasan disebut sebagai pihak yang lalai agar bisa dengan tepat dan akurat dalam menyelesaikan perselisihan baik dari sisi hukum positif.

2. Sumber daya manusia yang tidak menguasai secara keseluruhan tentang produk KPR. Hal itu yang harus lebih hati-hati dalam memberikan pelatihan kepada SDM, karena sekarang ini masyarakat lebih kritis mengenai produk KPR.

Upaya Peningkatan KPR pada PT Bank Tabungan Negara Kcp Dramaga Bogor dalam Segmentasi, Penetapan pasarsasaran dan pemosisian yang baik.

Untuk mendapatkan Segmentasi, Penetapan pasarsasaran dan pemosisian yang baik, salah satu upaya yang dilakukan Bank BTN ialah dengan meningkatkan Segmen pasar untuk mempertahankan target pasar yang baik terhadap konsumennya.

Pada dasarnya Bank BTN melakukan Segmentasi pasar yang baik untuk meningkat dan mencapai tujuan dengan penjualan yang maksimal serta meningkatkan target pada konsumen yang berkualitas dan bermutu dengan SOP (Standar operasioanal prosedur) kerja yang ada. Dan untuk mengetahui jumlah segmen pasar dan target pasar yang dilakukan oleh konsumen tergantung pada kuatnya dorongan, jumlah informasi yang sudah dimiliki. Adapun beberapa yang dilakukan dalam memberikan informasi dengan meningkatkan segmentasi, penetarapan pasarsaran dan pemosisian pada produk KPR sebagai berikut :

1. Manfaatkan media sosial

Di tengah kemajuan teknologi seperti saat ini, kita tidak bisa mengabaikan media sosial. Konsumen yang akan mencari infomasi melalui website Bank BTN menginformasikan kepada konsumen mengenai produk KPR.

2. Media Cetak

Suatu media yang statis dan mengutamakan peran-peran visual, promosi media cetak yang digunakan Bank BTN berupa standing banner, majalah, koran dan brosur. Dalam media cetak brosur terdapat keterangan tentang penjelasan produk KPR, keunggulan dan persyaratan pengajuan agar konsumen mudah menemukan dan mengenali produk yang dimiliki Bank BTN. Selain desain dan sisi brosur yang berkualitas, penyebaran brosur juga harus tepat sasaran yang sesuai dengan target pasar.

3. Pameran

Suatu kegiatan yang diselenggarakan sebagai media untuk menyampaikan ide atau gagasan kepada konsumen dalam produk tertentu seperti properti. Kegiatan pameran ini bentuk promosi yang dilakukan oleh Bank BTN dengan menampilkan Display kepada calon pembeli atau relasi.

\section{PENUTUP}


Berdasarkan pembahasan yang telah dijelaskan, maka kesimpulannya adalah sebagai berikut :

1. Segmentasi, pasarsasaran dan pemosisian produk KPR yang di lakukan oleh Bank BTN, salah satu komponen yang mendukung dalam bagaimana Segmentasi, pasarsasaran dan pemosisian yang digunakan oleh suatu proses atau badan usaha. Dan adapun untuk mengetahui Segmentasi, pasarsasaran dan pemosisian produk KPR sebagai berikut :

a. Segmentasi

Dalam segmentasi pasar untuk produk KPR meningkat mampu merealisasikan kenaikan KPR nonsubsidi sebesar 12,9\% menjadi 20,95\% hal ini diluar Trend bisnis perbankan. Selain itu, dengan pangsa pasar KPR terbesar akan terus mendukung program sejuta rumah pemerintah yang disebut KPR subsidi sehingga Bank BTN tetap berkonstribusi pada program sejuta pemerintah dan segmen pasar pada KPR cenderung bersifat homogen dalam segala aspek perubahan yang digunakan untuk pasar konsumen yaitu : Geografis, Demografis,dan Psikografis.

b. Pasarsasaran (Targeting)

Dalam menentukan target pasar produk KPR pada Bank BTN adalah dengan menentukan pasarsasaran berdasarkan evaluasi segmen pasar. Dalam target produk KPR pada Febuari 2020 untuk penyaluran KPR dengan aneka promosi diantaranya kolaborasi dan diskon biaya administrasi dan untuk nilai ijin prinsip KPR tersebut lebih tinggi dibandingkan target awal yang dibidik perseroan yaitu sebesar Rp. 13 Trilliun. Dan seperti yang diketahui APBN menganggarkan Rp. 11 Trilliun untuk memfasilitasi subssidi pembiayaan 102.500 unit pada tahun 2020 . Dan untuk pertumbuhan KPR nonsubsidi bisa tumbuh dikisaran $10-12 \%$ atau menyamai pertumbuhan kredit secara umum oleh Bank indonesia pada tahun 2020 karena banyak faktor yang mendukung.

\section{c. Pemosisian (Positioning)}

Pemosisian Bank BTN dikreditkan perumahan memang sangat jelas dan total kredit yang ada 89,9\% merupakan kredit KPR. Bank BTN menyasar KPR kelas menengah bahwa meski nilainya tidak terlalu besar, rupanya konsumen pada segmen ini memiliki daya beli yang kuat untuk mencicil rumah. Dari total kredit perumahan secara senilai Rp. 11 Trilliun yang mefasilitasi subsidi. Dan Bank BTN juga bergabung dalam World Savings and Reatail Banking Institute (WSBI) untuk memperluas jaringan sehingga keluar negeri, memperkuat Channel berbagai provinsi indonesia, dan penerapan Digital Banking untuk mempercepat proses pelayanan. Meski berurusan dengan debitur dalam jumlah banyak, bukan berarti Bank BTN melupakan prinsip Good corporate governance (GCG). Disisi Back and Back, Bank BTN memperkuat sistem dan SDM dibagian Collection. Selain itu, harus memperdekatkan diri dengan konsumen melalui berbagai cara atau bisa mulai dari website, pameran perumahan, serta memperkuat relasi dengan jaringan agen. Bank BTN menjadi Bank KPR dengan Market Share terbesar di Indonesia dengan porsi 30,6\% disektor nonsubsidi. Sedangkan di KRP-FLPP-BBTN memiliki Market share hingga 98\%.

2. Hambatan dalam Segmentasi, Penetapan pasarsaran dan pemosisian produk KPR pada Bank BTN dalam meningatkan suatu usaha, banyak rintangan yang harus kita hadapi dengan baik. Adapun faktor-faktor yang berpengaruh signifikan terhadap Segmentasi, penetapan pasarsasaran dan pemosisian yaitu proses pembiayaan KPR di Bank BTN seperti misalnya legalitas rumah tanah, pemilihan notaris yang kurang hatihati dalam melakukan proses KPR dan Sumber daya yang tidak meguasai secara keseluruhan tentang produk KPR.

3. Upaya produk KPR untuk mendapatkan Segmentasi, pasarsasaran dan pemosisian yang baik, salah satu upaya yang dilakukan Bank BTN ialah dengan meningkatkan Segmen pasar untuk mempertahankan target pasar yang baik terhadap konsumennya. 
Bank BTN juga melakukan Segmentasi pasar yang baik untuk meningkatkan dan mencapai tujuan dengan penjualan yang maksimal serta meningkatkan target pada konsumen yang berkualitas dan bermutu dengan SOP (Standar Operasional Prosedur). Dan untuk mengatahui jumlah segmen pasar dan target pasar yang dilakukan oleh konsumen tergantung pada kuatnya dorongan.

\section{DAFTAR PUSTAKA}

Jahnson Carla \& Lele Monle. 2012. Prinsip-Prinsip Pokok Periklanan Perspektif Global, Edisi 1, Jakarta

Tjipto, Fandy. 2015. Strategi Pemasran.Edisi 4. Andi, Yogjakarta

Abdullah, Thamrin, dan Francis Tantri.2012. Manejemen Pemasaran, PT Raja Grafindo, Depok

Kotler, Philip, dan Armstrong, Gary. 2010. Prinsip-Prinsip Pemasaran.Edisi 2012 Jilid 2, Erlangga , Jakarta.

Tjiptono,Fandy. dan Anastasia Diana.2016. Pemasaran,Esensi dan aplikasi. Publisher, Jakarta

Buchory Alma, 2011. Manajemen Pemasaran dan Pemasaran Jasa. Bandung: Alfabeta. Ma'aruf, Hendri. 2005. Pemasaran Ritel, Jakarta: Gramedia.

Wijayanti, Titik.2012.Marketing Plan dalam Binis, PT Media Komputindo, Jakarta.

Tjiptono, Fandy, 2010. Strategi Pemasaran. Edisi III, Andi, Jakarta.

Http://e-Journal.uajy.cc,id/3906/3/2em17651.pdf (Diakses 20 Februari 2020)

Http://Repository.ekuitas.ac.id/bitsream/handle/.123456789/235/BAB\%202.pdf?seq uence $=7$ ISAllowed $=y$ (Diakses 20 Februari 2020)

Https://Respository.Widyatama.ac.id/xmlui/.bitstream/Handle/123456789/2712/.Ba b\%25202.pdf ?sequence $=4$ (Diakes 23 Februari)

Https://www.Hestanto web.id (Konsep Pemasaran)

Https://eprints.perbanas.ac.id/295/3/bab\%201.pdf

Https://eprints.uns.ac.id/Deni Fitriyanto.2009. Penerapan Strategi Segmentasi Targeting Positioning, Surakarta; Tugas Akhir.

Https;//Repository.Ipb.ac.id/Jspui/bitsteam/Rifi Noviany. 2014. Analisis Strategi Bauran Pemasaran BTN Prima Pada PT Bank Tabungan Negara Kcp Bogor. Bogor;Tugas Akhir. IPB 